\title{
Public Administration, NGOs and Private University in Teaching in Professional Master's Courses
}

\author{
Diego Santos Vieira de Jesus, João Luiz de Figueiredo \\ ESPM-Rio, Rio de Janeiro, Brazil \\ Email:dvieira@espm.br, joao.silva@espm.br
}

How to cite this paper: de Jesus, D. S. V., \& de Figueiredo, J. L. (2018). Public Administration, NGOs and Private University in Teaching in Professional Master's Courses. Creative Education, 9, 1713-1725. https://doi.org/10.4236/ce.2018.911125

Received: August 5, 2018

Accepted: August 28, 2018

Published: August 31, 2018

Copyright (c) 2018 by authors and Scientific Research Publishing Inc. This work is licensed under the Creative Commons Attribution International License (CC BY 4.0).

http://creativecommons.org/licenses/by/4.0/ c) (i) Open Access

\begin{abstract}
The aim is to examine the relations between public administration, NGOs and private universities in teaching in professional master's courses, taking as a case study the relationship between the Municipal Secretary of Culture of Rio de Janeiro, the NGOs managers of cultural equipments in the city and ESPM-Rio in proposing tasks and activities for students for the Professional Master's Program in Creative Economy Management. The central argument points out that the interaction between the public administration, the market and the university favors the exchange of knowledge and creates practical learning situations for students.
\end{abstract}

\section{Keywords}

Public Administration, NGOs, University, Professional Master's Program, Cultural Projects

\section{Introduction}

In the contemporary world, a greater qualification is required for professionals-especially masters and PhDs-who do not necessarily work with teaching, but are focused on activities outside the academic life. Given the greater relevance of innovation and knowledge, the Stricto sensu graduate programs in Brazil gradually assumed an important role in the preparation of professionals, even though their focus continues to be primarily on research and training for teaching. Increasing numbers of masters and $\mathrm{PhDs}$ leave the academic life to meet the demands of governments, companies and third-sector organizations for professionals with a solid academic background. With the greater supply of masters and $\mathrm{PhDs}$ out of the academic life, scientific knowledge has been transferred not 
only to private profit-making organizations, but also to public institutions and various third-sector organizations for the formulation and implementation of public policies (Ribeiro, 2005).

In this context, professional master's programs gain more visibility as they seek to meet the demands of companies, governments and civil society organizations for personnel with a level of qualification that goes beyond the knowledge offered in undergraduate courses and is capable to connect theoretical knowledge and practical demands of professional life. They contribute to the generation of new processes and technical or technological products capable of enhancing innovation, competitiveness and sustainability of organizations. For the implementation of such master's programs, educational institutions need not only professors with different profiles from those who are strictly dedicated to academic research, but new materials, technological structures, research and investments to match the courses with the demands of the market. The interdisciplinary professional master's programs accumulate expertise from multiple areas of knowledge and generate experiences and activities for the development of transversal competences, which are directed to the realization of interventions aimed at market, political and social solutions (Castro, 2005).

In Brazil, private universities have developed professional master's programs-many of which are interdisciplinary-in the light of a large demand of paying students interested in further qualification. In 2016, ESPM-Rio started to offer the Professional Master's Program in Creative Economy Management (MPGEC, its acronym in Portuguese). Creative economy refers to sectors based on talents and individual and collective skills such as advertising, architecture, crafts, design, fashion, film, interactive leisure software, music, performing arts, publishing, radio, TV and museums. The objective of the master's program offered by ESPM-Rio is to train specialists in the application of managerial, legal and operational knowledge in these sectors, with creative, investigative and reflexive skills in Design, Communication and Management (ESPM, 2016).

The aim is to examine the relations between public administration, NGOs and private universities in teaching in professional master's courses, taking as a case study the relationship between the Municipal Secretary of Culture (SMC, its acronym in Portuguese) of Rio de Janeiro, the NGOs managers of cultural equipment in the city and ESPM-Rio in proposing tasks and activities for students for the Professional Master's Program in Creative Economy Management, in the discipline "Advanced Management of Cultural Projects for Creative Cities", taught by the authors of this study'.

The discipline was offered in the second semester of 2017 for a group of ten master's program's students, whose research is located within the research line "Strategic Management of Creative Sectors". These students were in the second period of the master's program's degree course. The central argument points out ${ }^{1}$ At MPGEC, most disciplines are offered by two professors for the same class. In general, both are present in class and have different competencies to strengthen students' skills development. 
that the interaction between public power, market and higher education institutions (HEIs) favors the transfer of knowledge from the universities to the public institutions and companies, while creating practical learning situations for students, such as the formulation of projects that allow governments and social actors new ways of attracting investments; improvements in the communication strategies of these actors with society; and the development of activities that promote cultural diversity and the social integration of low-income populations. This process of interaction also contributes to regional development based on a "triple helix", which engages the government, the market and the university in efforts in this direction (Etzkowitz, 2009).

\section{Theoretical Framework}

The increasing demands for a more diversified and competitive labor market have brought challenges for the training and requalification of professionals by HEIs, which had to adopt new curricular directions and incorporate technological innovations and instrumental knowledge linked to market practices. In this context, professional master's programs began to be developed to diversify the teaching practice in Stricto sensu graduate courses and deal with the tensions between academic values and market pressures (Andrade et al., 2004). As recent institutionalized practices, these master's programs seek to develop learning from theoretical-conceptual frameworks and practical tasks in the training of professionals as managers, guided by principles such as flexibility and innovation. Teaching is practice-oriented and encompasses hybridization between thematic axes, experiences and simulations. Although the academic bias predominated in the genesis and development of graduate education in Brazil to prepare teaching personnel and institutionalize research, the stimulation of an alternative training to academic resources was regulated in the mid-1990s and faced the resistance of traditional academic models, sedimented in the constitution of the graduate programs. Some professional master's programs with a more general profile seek to train multi-qualified professionals and generally attract students with previous experience, who often come from governments, companies and sectors of civil society. Others focused on qualifying professionals for specific sectors, enabled specialization to manage concrete issues and attracted beginners or experienced people, often in the search of growth or professional reallocation (Fischer, 2005). Others combine both guidelines, such as MPGEC at ESPM-Rio.

Both in academic and professional master's programs, the immersion of the student in research takes place. However, the professional master's degree differs from the academic one, as the result sought in the first-the product-is the formation of a professional who, in the environment outside the university, can mobilize the research activity to add value to activities carried out in the corporate, governmental or social dimensions (Ribeiro, 2005). Moreover, while the academic master's degree in general motivates a physical withdrawal from the 
work environment, the professional master's degree carries the possibility that learning is developed based on the student's professional practice and, in a concomitant way, minimizes the gaps between the academic environment and the market, as well as the readaptation needs after the course is completed. The final work of a professional master's degree may differ from the dissertation, typically required as a prerequisite for the completion of the academic master's degree. The final work of the professional master's degree may, for example, bring proposals for action that have an impact on the student's professional environment, such as a business plan or an institutional product to be used by the professional organization to which the student is linked. The same applies to the works developed in the disciplines of such master's degree. In this sense, professional training and research developed by the student are closely related (Moreira, 2004). The comparison between a professional master's degree and an academic one is presented in Table 1.

The work carried out by students in a professional master's program is typically oriented towards the resolution of issues in their professional field, the identification of gaps and the promotion of interventions to minimize or eliminate these gaps. In the case of interdisciplinary professional master's programs, the student can develop interventions based on the transversal dialogue among multiple areas of knowledge to solve concrete problems and propose alternatives to new issues (Ribeiro, 2005). The work of conclusion of the professional master's degree usually brings an applied research to the resolution of issues, with impact to the system to which this investigation refers. In addition to the exposure of results and their analysis and discussion, such work can bring recommendations of practical interventions, supported by the theoretical-conceptual discussion and encompass case studies and development of technologies, software and patents (Fischer, 2005).

In the scope of interdisciplinary professional master's degrees, the tasks imply the commitment to a critical-reflexive position of the university, the permanent

Table 1. Professional master's degree vs. academic master's degree.

\begin{tabular}{ccc}
\hline \multirow{2}{*}{ Aspects } & \multicolumn{2}{c}{ Master's degree } \\
\cline { 2 - 3 } Institutionalization & Professional & Academic \\
Teaching & Recent & Not recent \\
\hline $\begin{array}{c}\text { Hybridization between thematic axes, } \\
\text { experiences and simulations } \\
\text { Mobilization of research activity in } \\
\text { non-academic dimensions } \\
\text { Physical withdrawal from the work } \\
\text { environment }\end{array}$ & Intense & Theory-oriented \\
& Yes & No \\
Final work & No & Yes \\
& Dissertation, business \\
plan, institutional & product & Dissertation
\end{tabular}


exercise of complementation between theory and practice and the continuous development of transversal competences that adapt to different situations. The teaching practices transcend the strictly pedagogical dimension and are linked to the ways of organizing knowledge in society, which requires high flexibility of the professors to adapt to the profiles of each class and the encouragement to exchange experiences among the public sector, private companies and social movements. Students develop research skills, organizational analysis tools, and proactive posture to deal with differences and teamwork (Andrade et al., 2004).

In the research line of Strategic Management of Creative Sectors, MPGEC-an interdisciplinary professional master's program-has as one of its objectives to develop in the student skills for the formulation of cultural projects for creative cities. The concept of "creative city" is often used in reference to cities in which the articulation between social and artistic activities, creative sectors and government produced a cultural effervescence that attracted talents, promoted social diversity and strengthened the creative potential of companies and institutions (CCTC, n.d.). However, for Landry (2011: pp. 11-14)—one of the main authors to reflect on the concept-, the creativity of a city applies to multiple fields that transcend the creative sectors: public administration must promote social innovations with creativity in areas such as health, social services and governance. These cities bring together culture-related to urban identity and heritage-; communication-the physical and technological models of linking inhabitants and the minimization of conflicts; and cooperation, understood as the interaction and full acceptance of diversity. In order to stimulate opportunities or solve urban problems in a creative city, there is a need not only for a gross infrastructure of cultural equipment, an efficient transportation system and basic sanitation, but a soft infrastructure that includes a skilled and flexible workforce; thinkers, creators and dynamic implementers; and extensive intellectual infrastructure (Chantelot et al., 2011).

\section{Methodological Considerations}

The data collection for this study was based on a participant observation of the performance of the students in the accomplishment of the task proposed by the SMC within the scope of the discipline "Advanced Management of Cultural Projects for Creative Cities". The purpose of the discipline was to stimulate the development and application of tools and methodologies for the elaboration and management of cultural projects for creative cities. The significance of the proposed projects is to bring practical interventions to the city that can promote cultural diversity and social integration of low-income populations.

Initially, the proposed task was the elaboration of a project of financial and cultural sustainability for the cultural canvases and arenas in the city. Cultural canvases are arena theaters covered by synthetic canvases, located in Rio's suburbs. They were created by the voluntary work of cultural and artistic groups from the use of the coverage of debate centers of the United Nations Conference 
on Environment and Development, known as Rio 92. In such spaces, cultural activities are offered, such as concerts, plays, workshops, art fairs, crafts and samba rounds. They are now co-managed by NGOs and the SMC and are maintained with funds transfers and money from the activities developed therein. With the great repercussion of canvases, Rio de Janeiro's City Hall expanded the initial scope of the initiative and created the cultural arenas, with larger spaces, capacities and funds than the canvases (Prefeitura do Rio de Janeiro, 2018). Considering that Rio de Janeiro has 10 cultural canvases and 4 cultural arenas and time was short for the project to be carried out-the discipline was offered over three months, from July to September 2017-, we requested that SMC selected an arena and a canvas for the execution of the task, so that they could serve as pilots for the realization of future projects for the other equipments. The choices were the Lona Cultural Terra, located in the neighborhood of Guadalupe, and the Arena Carioca Abelardo Barbosa-Chacrinha, located in the neighborhood of Pedra de Guaratiba. These equipments were chosen because they faced the strongest problems in achieving financial and cultural sustainability and are located in some of the poorest neighborhoods in Rio de Janeiro.

The aim in this stage of the research conducted by the authors was to compile the most relevant actions taken by the students in the planning and the formulation of the project, namely: the collection of official documents with data about the canvas and the arena and the demographic and sociocultural profile of communities in which they are located; interviews with SMC members and selected equipments' managers, who are members of NGOs that have won bids to manage them; visits to the canvas and the arena for local information collection; the writing of the project by the students, under the guidance of the professors; and the presentation of the project to SMC and NGO managers.

In the analysis of the collected data, we sought qualitatively to interpret the students' actions in the stages of the elaboration of the project to investigate the interaction of the SMC and the managers of the selected canvas and the arena with the students and the professors responsible for the discipline at ESPM-Rio. In addition, we sought to compare the content of the final report presented by the students to SMC, prepared under our guidance, with the theoretical-conceptual basis about the roles of professional master's programs in the training of students to solve issues in their area of expertise.

\section{Results}

The initial contact with SMC was established by the authors in June 2017, before the beginning of the university term. On the occasion, we explained to SMC representatives the MPGEC's objectives, the aims of the discipline we would teach and the task to be proposed to students. With the positive signals from the members of the City Hall regarding the partnership with ESPM-Rio, we asked them to propose a task that would allow the realization of an intervention project that would contribute to the better execution of the city's cultural policy. 
Based on the SMC's proposal for a financial and cultural sustainability project for Lona Cultural Terra and the Arena Carioca Chacrinha, the authors structured their classes in two moments. In the first one, the exposition and the discussion of conceptual and theoretical content were aimed at the elaboration of projects for creative cities in all stages, namely: 1) initiation: definition of guidelines and authorization of the project; 2) planning: refinement of objectives, planning of actions and detailing of the scope of the project; 3) implementation: integration of resources and team to carry out the plan; 4) monitoring: regular assessment of development; 5) closure: formalization of acceptance of the product and its termination (Campanario et al., 2009). In carrying out the activity proposed by SMC, the focus would be on the first three stages. In the second moment of the class, the students dedicated specifically to the task assigned by SMC, under the guidance of the two professors. The final grade awarded to the students was composed as follows: $50 \%$ corresponded to the printed report handed to SMC, and the other 50\% represented the individual performance of the student in the presentation of the project to SMC, made in the last class of the discipline. The task proposed by the SMC was presented to the students in the first two classes.

In the formulation of the project, specific tasks were assigned to the ten participating students in a meeting with the professors. Each group of three or four students was responsible for at least two different tasks, such as interviews with SMC students and equipment managers, local visits, elaboration and presentation of the final document. Interviews with SMC members and equipment managers were held in the second part of the classes at ESPM-Rio's facilities. In this part of the class, students were also able to use the classroom for partial meetings about the content of the project and the computer labs for the preparation of the report and the preparation of the presentation to SMC. Some questions needed to prepare the document were emailed to SMC members and equipment managers. They also sent the necessary data to the formulation of the students' diagnosis of the situation. Outside the class period, some students and the professors visited the equipments to gather information with people who participate in the cultural events at the canvas and the arena and collect data on the areas where the cultural equipments are located.

From the debates in the first classes about the theoretical and conceptual content of the discipline between the professors and the students in the initiation of the project, a structure of the document to be presented to SMC was established. In the introduction, the objectives of the project, its didactic importance, its relevance in terms of social intervention and a brief presentation of the other sections would be included. The second section would deal with the importance of canvases and cultural arenas, with a brief historical description of the creation and transformation of these equipments and the justification of their relevance in cultural politics and social innovation in a creative city such as Rio de Janeiro. The third section would bring a diagnosis of the situation of the Lona Cultural 
Terra and the Arena Carioca Chacrinha. It would encompass a characterization of the legal model and the organizational structure of these cultural equipments, as well as their qualification and location and the characterization of the area in which they are located through socioeconomic data; an analysis of results in terms of audience and box office of the cultural events; research into the cost structure and the revenue model; the managers' views on the challenges of leading such equipments; and the identification of the problems they face from a SWOT Analysis-a tool used to make scenario analyses, which takes into account strengths, weaknesses, opportunities and threats-and the identification of critical success factors. The SWOT Analysis is presented in Table 2.

The fourth section of the project would bring the proposed solutions to the problems, including possible strategies generated from the cross-SWOT analysis, an action plan based on the results of such an analysis and the proposition of an alternative business modelling. The fifth section would cover proposals for cultural projects for such equipments and contain details of cultural products and actions; their general and specific objectives; the expected results and indicators; the mapping of target audiences; the strategies that would provide the feasibility of the project; a schedule of activities; a communication plan for the equipments; and the specification of the budget and alternative means of raising funds for the cultural activities to be carried out. In the final considerations, the academic and didactic results of the project and the expected results for the financial and cultural sustainability for the equipments indicated by SMC would be presented.

In the collection of official documents with data about the selected canvas and

Table 2. SWOT analysis.

\begin{tabular}{|c|c|c|}
\hline & Helpful to achieving the objectives & Harmful to achieving the objectives \\
\hline \multirow{10}{*}{ Internal origin } & & Weaknesses: \\
\hline & Strengths: & W1. Limited box office \\
\hline & S1. City Hall resources & W2. Limited seats \\
\hline & S2. Reputation and legitimacy & W3. Limited fund-raising strategies \\
\hline & S3. Great involvement of managers & W4. Lack of strategic planning \\
\hline & $\begin{array}{c}\text { S4. Democratization of culture and } \\
\text { education }\end{array}$ & $\begin{array}{l}\text { W5. Lack of communication, } \\
\text { marketing and brand identity }\end{array}$ \\
\hline & S5. Community involvement & W6. Lack of training of managers \\
\hline & S6. Diverse activities in the & and new leaders \\
\hline & equipments & W7. Problems in the maintenance \\
\hline & & of the equipments \\
\hline \multirow{9}{*}{ External origin } & Opportunities: & \\
\hline & O1. Strength of Rio de Janeiro's & Threats: \\
\hline & creative economy & T1. Bureaucratic obstacles \\
\hline & O2. Relationship between the City & T2. Increasing violence \\
\hline & and culture & T3. Increasing political instability \\
\hline & O3. Diversity of funding sources & T4. Increasing financial crisis \\
\hline & O4. Great talent offer & T5. Political discontinuity \\
\hline & O5. Increased social actors' & T6. Threats to cultural diversity in \\
\hline & $\begin{array}{l}\text { engagement with social and cultural } \\
\text { policies }\end{array}$ & Rio de Janeiro \\
\hline
\end{tabular}


arena and the demographic and sociocultural profile of the communities in which they are located, it was possible to perceive that the great challenge of the selected cultural equipments is related to the increase of the revenue, because, despite the expressive numbers of public attendance at the various cultural events and workshops offered in the spaces, the average ticket price is very low due to the practice of popular prices and gratuities, appropriate to the socioeconomic profile of the resident population in the nearby areas. The public resources are clearly insufficient for the maintenance of these cultural equipments, especially in the case of the Lona Cultural Terra, which receives 25 thousand reais (6.7 thousand dollars) per month. Such value represents a third of the value received by the Arena Carioca Chacrinha. It is worth mentioning that, of this transfer, 5\% return to the City in the form of taxes, so that the net transfer to the Lona Terra and the Arena Chacrinha are, respectively, 23,750 reais (6.4 thousand dollars) and 71,250 reais (19.2 thousand dollars). On the other hand, the equipments have their light and water bills paid by the municipal administration.

In the interviews with the SMC members and managers of the selected equipments, as well as during the visits to the canvas and the arena, the students sought to identify the strategies adopted to guarantee the permanent provision of events for the population, the managers' view on the management model and the linkage of the local population with the equipments. Some interviews were conducted in the ESPM-Rio classrooms, and the visits occurred during the week in the afternoon, so that the spaces were occupied by workshops.

The interviews showed that the great concern of the equipments' managers is to guarantee the offer of cultural events and workshops in areas of the city that are not served by the private culture market. The general solution for the managers is to offer workshop producers and instructors the integrity of the box office and tuition fees, so that, on the one hand, they could attract those interested in offering cultural productions and varied workshops at popular prices, but, on the other hand, the equipments could not retain the financial value generated by the cultural events. The equipments generated an important cultural value, but did not capture financial value, so that the dependence of scarce public resources remained. In addition, because the cost structure of the equipments was very limited due to the scarcity of resources, managers were unable to dedicate themselves to strategic activities and had to divide their attention into multiple daily tasks.

It is evident, from the data collected by the students, the motivation of the equipments' managers to guarantee the supply of culture and workshops for the local populations, but it is also clear that they would like to be able to concentrate on more strategic activities, which would enable reducing the dependence on public resources and expanding equipment revenue so they could improve infrastructure. In the opinion of the managers, it was urgent to rethink the equipments' management model. 
During the visits to the cultural equipments, the students perceived the daily dynamics of the spaces and mainly the ways in which they are appropriated by the local populations. The variety of workshops diffused and shared artistic, cultural and technological knowledge, while cultural events facilitated access to culture for people living in areas of the city with a reduced supply of cultural equipments. In addition, it should be mentioned that, often, the stages of the equipments were occupied by local artists who found the possibility of starting their careers there.

In the elaboration of the project by the students under the guidance of the professors, opportunities were identified for the extension of the financial sustainability of the cultural equipments. They were based on the change of the management model that would start to be organized into networks, so that the search for sponsors and supporters would no longer be faced individually and would be integrated by the 14 cultural facilities of the network of canvases and cultural arenas of the city of Rio de Janeiro. The networking of equipments is provided by the Regulatory Framework of Civil Society Organizations (Brasil, 2014). In addition, managers were also suggested that a small percentage of the monthly fees paid by workshop participants should be directed towards maintaining the infrastructure of the cultural facilities. In the field of communication, students also emphasized the need for a greater presence of the equipments in social networks to broaden the connection with the public. Finally, considering that, in 2018, the 25th anniversary of the creation of the first Cultural Canvas would be celebrated, the creation of a project for each equipment was suggested with the objective of retaking the affective bond with the artists that inspired the names of each equipment and also with others of great knowledge of the public and who, at some point in their careers, presented themselves in the aforementioned cultural spaces.

In the presentation of the project to the SMC and the equipments' managers, in addition to the analysis produced by the students, the students carried out another SWOT analysis exercise with the present leaders and managers, since the main solutions must be based on the knowledge of those who use the cultural equipments. At that moment, the importance of the professional master's program in terms of the interaction with society was clear in the search for innovation in the solution of social issues, in this case with respect to the cultural canvases and arenas in a creative city such as Rio de Janeiro.

\section{Analysis and Discussion}

In the case of the partnership between the SMC and ESPM-Rio in proposing activities for MPGEC students, it is possible to identify the existence of diverse forms of articulation of relations between government, NGOs and private universities in the practice of teaching in professional master's programs. The curricular structure and the offered teaching and professional experiences show a direct association with the demands brought by social and political agents, such 
as the SMC and the equipments' managers. They identify needs and opportunities and propose evaluation mechanisms to ensure that adequate responses are offered if demand changes over time.

The definition of the discipline "Advanced Management of Cultural Projects for Creative Cities", based on everyday issues in the social-political universe, encompasses the development of common interests between the university and the involved governmental institution and NGOs, in order to promote the exchange between the private higher education institution, the public power and the leadership of the NGOs that manage the equipments and stimulate the development of products and services that simultaneously contribute to the preparation of the students. As developed by Fischer (2003), one can say that the orientation towards the solution of concrete management problems incorporated an intervention project for fundraising, improvement of communication, formation of human resources and development of cultural activities. The teaching environment-marked by the diversity of students, with professionals working in public and private sectors and social organizations-has generated a rich space in terms of exchange of experiences and complementarity of knowledge in the elaboration of the project presented to the SMC.

In line with the idea developed by Ribeiro (2005), the students were immersed in research to generate a product that reverberated outside the university. In the elaboration of such a product, they offered diagnoses for problems and carried out the research with the purpose of adding value to the activity in social scope. Instead of physically moving away from the work environment, the student of the professional master's degree mitigated the gaps between the academic environment and the market, as well as the need for readaptation to the work environment, which is in line with the argument brought by Moreira (2004). With regard specifically to the development of projects for creative cities, the proposed task allowed, in agreement with Landry (2011), that creativity transcend the creative sectors themselves and embrace social innovations in the public sphere, particularly in the administration of cultural equipments and the provision of services to low-income populations, which stimulates social inclusion. With the project developed by the students, not only elements of the urban identity of Rio de Janeiro were reinforced, but forms of communication were encouraged for the rapprochement between the inhabitants of the city and the creation of spaces for the continuous expression of the cultural diversity represented by the communities in which the canvas and the arena in focus were located. To do so, the MPGEC project sought to propose solutions to problems in the gross infrastructure of the cultural equipments, but also enable a soft one, which included communication efforts and the greater qualification of the managers to capture resources and maintain the cultural projects developed in the equipments, including the dimensions developed by Chantelot et al. (2011).

\section{Final Considerations}

The professional master's programs enable the experimentation of innovations 
and the interdisciplinarity in curriculum building and teaching and learning methodologies for the development of flexible and socially desirable skills, accompanied by continuous evaluation and monitoring (Fischer, 2005). The evaluation of the professional master's programs can consider results in relation to the aggregation of value to the students through the works of conclusion and the activities carried out during the courses. When such activities are situations in which the acquired scientific knowledge is applied to the sociopolitical or market environments, the professional master's programs bring benefits not only related to the profit for companies, but also to the solution of problems in terms of public policies and the improvement of social conditions. In this sense, to evaluate the quality of professional master's program, the production and the updating of data on the impacts of interventions proposed by students for the proposed cases and the destinations of the graduates are fundamental (Ribeiro, 2005).

To develop professional master's programs in Brazil, we suggest that the debate on public policies should encompass training and qualification, research, development and regulation of virtual platforms, for example. In terms of training and qualification, the dissemination of information and communication technologies and the use of multidisciplinary management practices should be encouraged (Bakhshi, 2014).

Rather than simply training managers, professional master's programs should also enable students to develop broader views on planning and prospecting, particularly in sectors where services are inefficient or insufficient to meet citizens' needs, including the cultural ones (Barros et al., 2005). They stimulate a critical perception of the reality in which these students are immersed and encourage the development of proposals to solve issues that affect the lives of populations. In this sense, the relations between public administration, NGOs and private universities in teaching in professional master's courses can create practical learning situations for students. These relations may generate conditions for the elaboration of projects that create new ways of attracting investments, improve the communication strategies of political and economic actors with society, and strengthen cultural diversity and social integration.

\section{Conflicts of Interest}

The authors declare no conflicts of interest regarding the publication of this paper.

\section{References}

Andrade, C., D’Ávila, C., \& Oliveira, F. (2004). Um olhar sobre a práxis pedagógica do mestrado profissional em Administração da Universidade Federal da Bahia. Revista Brasileira de Pós-Graduação, 1, 81-96.

Bakhshi, H. (2014). Manifesto pela economia criativa: um ponto de vista britânico. In L. Goldenstein, P. Rosselló, \& F. Arruda (Eds.), Novas direções na formulação de políticas para a economia criativa (pp. 96-109). London, São Paulo: The British Council.

Barros, E. C., Valentim, M., \& Melo, M. A. A. (2005). O debate sobre o mestrado profis- 
sional na Capes: trajetória e definições. Revista Brasileira de Pós-Graduação, 2, 124-138.

Brasil (2014). Lei 13.019/2014. Marco regulatório das organizações da sociedade civil. http://www.planalto.gov.br/ccivil_03/_ato2011-2014/2014/lei/113019.htm

Campanario, M. A., Maccari, E. A., Silva, M. M., \& Santana, S. G. (2009). Desenvolvimento de um curso de mestrado profissional sob a perspectiva da gestão de projetos. Revista Brasileira de Gestão de Negócios, 11, 423-442.

Castro, C. M. (2005). A hora do mestrado profissional. Revista Brasileira de Pós-Graduação, 2, 16-23.

CCTC (n.d.). Cidade criativa. http://cidadecriativa.org/pt/cidade-criativa

Chantelot, S., Pérès, S., \& Virol, S. (2011). From Talent to Creative Cities: Toward a Conceptual Framework. 51 st European Congress of the Regional Science Association International, New Challenges for European Regions and Urban Areas in a Globalised World, Barcelona, 30 August-3 September 2011.

ESPM (2016). Mestrado Profissional em Gestão da Economia Criativa. http://www2.espm.br/mestrado-profissional-em-gestao-da-economia-criativa-rio-de-ja neiro/o-programa

Etzkowitz, H. (2009). Hélice tríplice: universidade-indústria-governo: inovação em movimento. Porto Alegre: EDIPUCRS.

Fischer, T. (2003). Seduções e riscos: a experiência do mestrado profissional. $R A E, 43$, 119-123. https://doi.org/10.1590/S0034-75902003000200010

Fischer, T. (2005). Mestrado profissional como prática acadêmica. Revista Brasileira de Pós-Graduação, 2, 24-29.

Landry, C. (2011). Prefácio. In A.C.F. Reis \& P. Kageyama (Eds.), Cidades criativas: perspectivas (pp.7-15). São Paulo: Garimpo de Soluções.

Moreira, M. A. (2004). O mestrado (profissional) em Ensino. Revista Brasileira de Pós-Graduação, 1, 131-142.

Prefeitura do Rio de Janeiro (2018). Lonas e Areninhas http://www.rio.rj.gov.br/web/smc/lonas-culturais

Ribeiro, R. J. (2005). O mestrado profissional na política atual da Capes. Revista Brasileira de Pós-Graduação, 2, 8-15. 